\title{
Influence of varieties, harvest frequency and nitrogen fertilization on dieback of short rotation willow bushes in a six-year cultivation cycle
}

\author{
Wpływ odmian, częstotliwości zbioru i nawożenia azotem \\ na zamieranie karp wierzby krzewiastej w 6-letnim cyklu uprawy
}

\author{
Leszek Styszko, Monika Ignatowicz
}

\begin{abstract}
Summary
In the years 2008-2013 the field experiments with 10 cultivars of willow were conducted in the field that belonged to Koszalin University of Technology. The nitrogen fertilizer was applied at various doses $(0,60,120$ and $180 \mathrm{~kg} / \mathrm{ha} \mathrm{N})$. The results revealed that the withering of willow rootstocks was highly impacted by the time of re-growing of shoots (years) and the frequency of harvesting. The doses of fertilizers and cultivars were the factors of secondary importance. Until the fourth year of vegetation the average percentage of withering of willow rootstocks amounted to $5.3 \%$. The increase in the number of dead rootstocks occurred during the fifth and sixth year of vegetation. The cultivars were classified according to their liability to withering as follows: very strong - Start (42.4\%), strong - Sprint (31.9\%), medium - 1054 (26.8\%), Jorr (25.0\%), Olof (24.1\%), 1047 (23.9\%), 1047D (23.7\%) and Turbo (20.6\%). The varieties Tordis and Ekotur showed the weak tendency for withering (13.6\%, 9.2\%, respectively). The increase of the fertilizer dose, in relation to the plots without fertilization, resulted in intensification of willow rootstocks withering. In the plots with 1 harvesting during the first 4-year rotation, on avarage $5.6 \%$ of rootstocks withered while in plots with the harvesting applied twice the withering amounted to $14.1 \%$. Moreover, it was analysed how individual cultivars responded (rootstock withering) to increased harvesting frequency. The studied cultivars were classified as follows: very strongly responding - Sprint and Start, strongly responding - 1047D, 1054 and 1047, with moderate response - Jorr, Turbo and with no response - Olof, Tordis and Ekotur.
\end{abstract}

Key words: willow; withering; cultivars; harvest; fertilization; nitrogen

\section{Streszczenie}

Badania polowe przeprowadzono na polu Politechniki Koszalińskiej w Kościernicy w latach 2008-2013. Dziesięć odmian wierzby nawożono czterema dawkami azotu (0,60, 120 i $180 \mathrm{~kg} / \mathrm{ha} \mathrm{N})$. W analizach wykazano, że na zamieranie karp wierzby duży wpływ miało wieloletnie odrastanie pędów i częstotliwość zbioru pędów, a mniejsze - dawki azotu i odmiany. Przeciętnie do czwartego roku uprawy zamarło 5,3\% karp wierzby, a wzrost liczby martwych karp na poletku nastąpił w 5. i 6. wegetacji. Odmiany pod względem ich skłonności do zamierania zakwalifikowano jako: bardzo silne - Start $(42,4 \%)$, silne - Sprint (31,9\%), średnie - 1054 (26,8\%), Jorr $(25,0 \%)$, Olof (24,1\%), 1047 (23,9\%), 1047D (23,7\%) i Turbo (20,6\%) oraz małe - Tordis $(13,6 \%)$ i Ekotur (9,2\%). Wzrost dawki nawożenia azotem w stosunku do obiektów bez nawożenia spowodował nasilenie zamierania karp wierzby. Na obiektach z 1-krotnym koszeniem w pierwszej, 4-letniej rotacji, zamarło przeciętnie 5,6\% karp, a przy 2-krotnym - 14,1\%. Odmiany wierzby pod względem ich reakcji na zamieranie karp przy zwiększonej częstotliwości koszenia zakwalifikowano, jako: bardzo silnie reagujące - Sprint i Start, silnie reagujące - 1047D, 1054 i 1047, średnio reagujące - Jorr i Turbo oraz niereagujące - Olof, Tordis i Ekotur.

Słowa kluczowe: wierzba; zamieranie; odmiany; zbiór; nawożenie; azot

Politechnika Koszalińska

Katedra Biologii Środowiskowej

Zakład Roślin Energetycznych

Śniadeckich 2, 75-453 Koszalin

Istyszko@wbiis.tu.koszalin.pl 


\section{Wstęp / Introduction}

Przy produkcji biomasy wierzbowej na cele energetyczne ważna jest obsada karp na hektarze w całym 25-letnim cyklu jej uprawy. Z praktyki wiadomo, że przy wieloletniej uprawie obsada karp na hektarze maleje w stosunku do pierwotnych nasadzeń. Zmniejszenie obsady karp wierzby na hektarze wpływa ograniczająco na plon biomasy pędów. Badania Stolarskiego (2009) wykazały, że zamieranie karp wierzby w pierwszym, 3-letnim cyklu, przy uprawie na madzie bardzo ciężkiej w okolicach Kwidzyna, zależało od odmiany, gęstości sadzenia oraz częstotliwości zbioru, jednakże nie przekraczało ono $10 \%$ założonej obsady, niezależnie od badanego wariantu. We wcześniejszych badaniach autorów w okolicach Koszalina wykonanych na glebie lekkiej o bardzo głębokim poziomie wody gruntowej (940-980 cm od powierzchni gruntu), ale przy dostatku opadów (753$1062 \mathrm{~mm}$ ), w pierwszym 2- lub 4-letnim cyklu uprawy, również zamarło mniej niż 10\% karp, ale już w siódmej wegetacji badane klony miały bardzo zróżnicowaną ilość martwych karp na poletku (od 10 do 90,8\%) (Styszko i wsp. 2013). W cytowanych badaniach u czterech klonów, przy nawożeniu kompostem $\mathrm{z}$ osadów komunalnych zamieranie karp malało, ale dodatkowe stosowanie nawozu Hydrofoska 16 w dawkach 562,5 i 1125 kg/ha u wszystkich dziewięciu klonów, zwiększyło to zamieranie.

Celem badań była ocena wpływu długości uprawy przy zróżnicowanej częstotliwości zbioru oraz nawożenia azotem na zamieranie karp u 10 odmian wierzby.

\section{Materiały i metody / Materials and methods}

W kwietniu 2007 roku na gruntach odłogowanych przez 10 lat $\mathrm{w}$ Kościernicy na polu doświadczalnym Politechniki Koszalińskiej założono doświadczenie z 10 odmianami wierzby wiciowej ze zróżnicowanym nawożeniem azotem. Doświadczenie składało się z okresu przygotowawczego (2007 rok), w którym wysadzono zrzezy wierzby o długości $25 \mathrm{~cm}$, a po zakończonej wegetacji - skoszono jednoroczne pędy zimą 2007/2008 i pierwszego 4-letniego okresu odrastania pędów (lata 2008-2011), gdzie po trzeciej wegetacji (listopad 2010 roku) skoszono połowę poletka, a po czwartej wegetacji (listopad 2011 roku) - skoszono całe poletko. Na lata 2012-2015 przypada drugi 4-letni cykl odrastania pędów wierzby. Na istniejących nasadzeniach wierzby, w 2007 roku założono doświadczenie ścisłe, metodą losowanych podbloków w układzie zależnym w trzech powtórzeniach, gdzie podblokami I rzędu były cztery kombinacje nawozowe $(0,60,120$ i $180 \mathrm{~kg} / \mathrm{ha} \mathrm{N})$, a II rzędu - dziesięć odmian wierzby (1047, 1054, 1047D, Start, Sprint, Turbo, Ekotur, Olof, Jorr i Tordis). Poletka miały powierzchnię $25,3 \mathrm{~m}^{2}$, na której wysadzano po 56 zrzezów wierzby w dwóch rzędach. Każdego roku oceniano zamieranie karp wierzby. Dla cechy tej wykonano analizę wariancji, a istotność źródeł zmienności oceniono testem F.

\section{Wyniki i dyskusja / Results and discussion}

Wegetacja wierzby w latach 2008-2013 rozpoczynała się w drugiej połowie kwietnia, a jej przebieg zależał od rozkładu opadów. Dane o opadach oraz o współczynniku hydrotermicznym Sielianinowa w latach badań zestawiono dla Koszalina w tabeli 1. (GUS 2007-2013). Pole doświadczalne w Kościernicy oddalone jest o $20 \mathrm{~km}$ od Koszalina w kierunku południowym. W latach badań w Koszalinie spadło 698-832 mm opadu, a w okresie wegetacji wierzby (IV-X) od $394 \mathrm{~mm}$ w 2013 roku do $548 \mathrm{~mm}$ w 2010 roku (tab. 1). Charakterystyka przebiegu pogody na podstawie opadów okazała się niewystarczająca ze względu na nierównomierny ich rozkład (tab. 1). Hydrotermiczne warunki ekstremalne (skrajnie suche i bardzo suche oraz bardzo wilgotne i skrajnie wilgotne) oznaczone współczynnikiem Sielianinowa (K) mieszczą się w przedziałach < 0,7 oraz $>2,5$ (Skowera i Puła 2004). Warunki skrajnie suche i bardzo suche wystapiły w kwietniu w latach 2009, 2010 i 2011 oraz w maju w latach 2008 i 2012. Natomiast warunki bardzo wilgotne wystapiły w kwietniu 2008 roku i październiku 2012 roku, a skrajnie wilgotne w maju i sierpniu 2010 roku oraz w październiku 2009 roku.

Strukturę procentową efektów głównych oraz ich interakcji w odniesieniu do udziału w łanie wierzby martwych karp, podano $\mathrm{w}$ tabeli 2 . Na podkreślenie zasługuje dominujące znaczenie lat odrastania pędów, a nieco mniejsze znaczenie - częstotliwości koszenia. Ten ostatni czynnik, wiąże się $\mathrm{z}$ częstotliwością zbioru w pierwszej 4-letniej rotacji, a mianowicie na I rzędzie każdego poletka dokonano 2-krotnie zbioru w odstępie 1 roku (listopad 2010 i 2011, tzn. po trzeciej i po czwartej wegetacji), a na II rzędzie koszono tylko 1-krotnie (listopad 2011 roku, tzn. po czwartej wegetacji). Znaczenie dawek azotu i odmian oraz interakcji tych czynników było mniejsze niż lat odrastania pędów i częstotliwości zbioru w pierwszej rotacji (tab. 2).

Wpływ lat $\mathrm{i}$ współdziałania lat $\mathrm{z}$ odmianami zestawiono $\mathrm{w}$ tabeli 3 . Do czwartego roku odrastania pędów przeciętnie było 5,3\% zamarłych karp, a wzrost martwych karp na poletku nastąpił w piątej (2012 rok) i szóstej wegetacji (2013 rok), mimo względnie korzystnego rozkładu opadów w 2012 roku. W maju, lipcu i sierpniu 2013 roku wystapiły warunki hydrotermiczne dość suche.

Odmiany wierzby charakteryzowały się zróżnicowaną skłonnością do zamierania karp (tab. 3). W okresie sześciu lat przeciętnie na doświadczeniu zamarło 9,8\% karp. Istotnie najmniej karp zamarło $u$ odmiany Ekotur (przeciętnie 2,9\%) i Tordis (przeciętnie 6,6\%), a najwięcej u odmian Sprint (przeciętnie 14,2\%) i Start (przeciętnie $14,0 \%$ ). Na wszystkich obiektach doświadczenia w szóstej wegetacji obserwowano nasilone zamieranie karp. W tej wegetacji uszeregowanie odmian pod względem ich skłonności do zamierania było następujące: bardzo silne Start (42,4\%), silne - Sprint (31,9\%), średnie - 1054 $(26,8 \%)$, Jorr $(25,0 \%)$, Olof $(24,1 \%), 1047$ (23,9\%), $1047 \mathrm{D}(23,7 \%)$ i Turbo $(20,6 \%)$ oraz małe - Tordis $(13,6 \%)$ i Ekotur (9,2\%). 
Wpływ dawek azotu i współdziałania tych dawek $\mathrm{z}$ odmianami wierzby zestawiono $\mathrm{w}$ tabeli 4 . Najmniej zamarłych karp było na obiektach bez nawożenia azotem (przeciętnie 5,1\%), a najwięcej - przy dawce $180 \mathrm{~kg} / \mathrm{ha} \mathrm{N}$ (przeciętnie 16,6\%). Wzrost nawożenia azotem w stosunku do obiektów bez nawożenia spowodował wzrost zamie- rania karp, np. o 33,3\% przy dawce $60 \mathrm{~kg} / \mathrm{ha} \mathrm{N}$, o $115,7 \%$ przy dawce $120 \mathrm{~kg} / \mathrm{ha} \mathrm{N}$ i o $225,5 \%$ przy dawce $180 \mathrm{~kg} / \mathrm{ha}$ N. Wpływ dawek azotu na zamieranie karp kształtował się podobnie w grupach odmian pod względem skłonności do zamierania karp.

Tabela 1. Opady [mm] oraz współczynnik hydrotermiczny Sielianinowa w Koszalinie w latach 2008-2013 według GUS (2007-2013)

Table 1. Precipitation [mm] and hydro-termal Sielianinow's coefficient in Koszalin in the years 2008-2013 according to GUS (2007-2013)

\begin{tabular}{|c|c|c|c|c|c|c|c|c|c|c|c|c|}
\hline \multirow{2}{*}{$\begin{array}{l}\text { Miesiąc } \\
\text { Month }\end{array}$} & \multicolumn{6}{|c|}{$\begin{array}{c}\text { Opady w latach } \\
\text { Precipitation in the years }[\mathrm{mm}]\end{array}$} & \multicolumn{6}{|c|}{$\begin{array}{l}\text { Współczynnik Sielianinowa }(\mathrm{K}) \text { w latach } \\
\text { Sielianinow’s coefficient }(\mathrm{K}) \text { in the years }\end{array}$} \\
\hline & 2008 & 2009 & 2010 & 2011 & 2012 & 2013 & 2008 & 2009 & 2010 & 2011 & 2012 & 2013 \\
\hline IV & 63 & 15 & 8 & 11 & 39 & 42,2 & 2,88 & 0,48 & 0,38 & 0,37 & 1,73 & 2,07 \\
\hline $\mathrm{V}$ & 16 & 66 & 109 & 57 & 16 & 51,1 & 0,42 & 1,80 & 3,74 & 1,44 & 0,39 & 1,19 \\
\hline VI & 64 & 97 & 47 & 86 & 89 & 64,4 & 1,33 & 2,33 & 1,06 & 1,74 & 1,99 & 1,37 \\
\hline VII & 56 & 103 & 79 & 107 & 119 & 54,5 & 1,01 & 1,82 & 1,25 & 2,02 & 2,18 & 0,98 \\
\hline VIII & 131 & 56 & 201 & 118 & 100 & 52,3 & 2,41 & 0,99 & 3,56 & 2,19 & 1,85 & 0,93 \\
\hline IX & 35 & 99 & 74 & 53 & 103 & 85,4 & 0,90 & 2,28 & 1,91 & 1,20 & 2,42 & 2,21 \\
\hline$X$ & 65 & 121 & 30 & 70 & 71 & 44,3 & 2,23 & 5,27 & 1,38 & 2,30 & 2,60 & 1,36 \\
\hline $\begin{array}{l}\text { Suma }(I V-X) \\
\text { Sum }(I V-X) \\
\end{array}$ & 430 & 557 & 548 & 502 & 537 & 394,2 & 1,51 & 1,92 & 1,99 & 1,67 & 2,01 & 1,34 \\
\hline $\begin{array}{l}\text { Suma (I-XII) } \\
\text { Sum (I-XII) }\end{array}$ & 742 & 761 & 802 & 698 & 832 & - & - & - & - & - & - & - \\
\hline
\end{tabular}

Tabela 2. Wpływ badanych czynników na zmienność zamierania karp wierzby

Table 2. Effect of studied factors on the variability of willow rootstocks withering

\begin{tabular}{|c|c|c|c|c|c|c|}
\hline \multirow{2}{*}{$\begin{array}{l}\text { Komponent wariancyjny } \\
\text { Variance component }\end{array}$} & \multirow{2}{*}{$\begin{array}{l}\text { Poziomy } \\
\text { czynnika } \\
\text { Factor } \\
\text { levels }\end{array}$} & \multirow{2}{*}{$\begin{array}{l}\text { Struktura procentowa } \\
\text { komponentów } \\
\text { wariancyjnych } \\
\text { Percentage structure } \\
\text { of variance components }\end{array}$} & \multicolumn{4}{|c|}{$\begin{array}{c}\text { Udział czynników głównych w zmienności interakcji } \\
\text { Contribution of main factors in the variability } \\
\text { of interaction }\end{array}$} \\
\hline & & & A & B & $\mathrm{C}$ & $\mathrm{D}$ \\
\hline $\begin{array}{l}\text { Odmiany wierzby D } \\
\text { Willow cultivars D }\end{array}$ & 10 & $1,7 * * *$ & & & & 1,7 \\
\hline $\begin{array}{l}\text { Dawki azotu C } \\
\text { Doses of nitrogen } \mathrm{C}\end{array}$ & 4 & $4,6 * * *$ & & & 4,6 & \\
\hline $\begin{array}{l}\text { Częstotliwość koszenia wierzby B } \\
\text { Frequency of willow harvesting B }\end{array}$ & 2 & $6,4 * * *$ & & 6,4 & & \\
\hline $\begin{array}{l}\text { Lata odrastania pędów A } \\
\text { Years of shoots regrowth A }\end{array}$ & 5 & $14,8^{* * *}$ & 14,8 & & 0,35 & 0,35 \\
\hline Współdziałanie DC - Interation DC & & $0,7 *$ & & & & \\
\hline Współdziałanie DB - Interation DB & & $5,8^{* * *}$ & & 2,9 & & 2,9 \\
\hline Współdziałanie CB - Interation CB & & $5,3 * * *$ & & 2,65 & 2,65 & \\
\hline Współdziałanie DCB - Interation DCB & & $2,7 * *$ & & 0,9 & 0,9 & 0,9 \\
\hline Współdziałanie DA - Interation DA & & $4,7 * * *$ & 2,35 & & & 2,35 \\
\hline Współdziałanie CA - Interation CA & & $6,6 * * *$ & 3,3 & & 3,3 & \\
\hline Współdziałanie DCA - Interation DCA & & 0,0 & & & & \\
\hline Współdziałanie BA - Interation BA & & $15,5^{* * *}$ & 7,75 & 7,75 & & \\
\hline Współdziałanie DBA - Interation DBA & & $10,3 * * *$ & 3,43 & 3,43 & & 3,44 \\
\hline Współdziałanie CBA - Interation CBA & & $9,6 * * *$ & 3,2 & 3,2 & 3,2 & \\
\hline $\begin{array}{l}\text { Współdziałanie DCBA } \\
\text { Interation DCBA }\end{array}$ & & 11,3 & 2,83 & 2,83 & 2,82 & 2,82 \\
\hline Suma - Sum & & 100,0 & 37,66 & 30,06 & 17,82 & 14,46 \\
\hline
\end{tabular}

Istotność przy poziomie: $*^{*} \alpha=0,05 ; *^{*} \alpha=0,01 ; * * * \alpha=0,001-$ Significance at: ${ }^{*} \alpha=0.05 ; * * \alpha=0.01 ; * * * \alpha=0.001$ 
Tabela 3. Wpływ współdziałania lat odrastania pędów z odmianami na zamieranie karp wierzby

Table 3. Effect of years of regrowth interaction with the cultivars on the withering of willow rootstocks

\begin{tabular}{|c|c|c|c|c|c|c|c|c|c|c|c|}
\hline \multirow{2}{*}{$\begin{array}{l}\text { Lata odrastania pędów } \\
\text { Years of shoots } \\
\text { regrowth }\end{array}$} & \multicolumn{11}{|c|}{ Procent zamarłych karp u odmian - Percent of dead rootstocks according to cultivars } \\
\hline & 1047 & 1054 & $1047 \mathrm{D}$ & Start & Sprint & Turbo & Ekotur & Olof & Jorr & Tordis & $\begin{array}{c}\text { średnia } \\
\text { mean }\end{array}$ \\
\hline 1 & 2,2 & 1,4 & 0,0 & 0,0 & 1,6 & 2,9 & 0,5 & 4,9 & 3,4 & 2,0 & 1,9 \\
\hline 3 & 4,0 & 2,7 & 3,1 & 1,3 & 1,4 & 5,6 & 1,8 & 11,8 & 6,7 & 5,8 & 4,4 \\
\hline 4 & 7,6 & 3,8 & 6,0 & 3,1 & 2,7 & 6,0 & 1,6 & 10,7 & 5,4 & 5,6 & 5,3 \\
\hline 5 & 13,6 & 15,6 & 15,4 & 23,0 & 33,5 & 10,7 & 1,3 & 6,5 & 9,6 & 5,8 & 13,5 \\
\hline 6 & 23,9 & 26,8 & 23,7 & 42,4 & 31,9 & 20,6 & 9,2 & 24,1 & 25,0 & 13,6 & 24,1 \\
\hline $\begin{array}{l}\text { NIR }(0,05) \\
\operatorname{LSD}(0.05)\end{array}$ & \multicolumn{10}{|c|}{$7,8^{*}$} & $2,5^{*}$ \\
\hline $\begin{array}{l}\text { Średnia dla odmian } \\
\text { Mean for cultivars }\end{array}$ & 10,3 & 10,1 & 9,6 & 14,0 & 14,2 & 9,2 & 2,9 & 11,6 & 10,0 & 6,6 & 9,8 \\
\hline $\begin{array}{l}\operatorname{NIR}(0,05) \\
\operatorname{LSD}(0.05)\end{array}$ & \multicolumn{10}{|c|}{$3,5^{*}$} & - \\
\hline
\end{tabular}

Istotność przy poziomie: $*_{\alpha}^{*}=0,001-$ Significance at: $*_{\alpha}^{*}=0.001$

Tabela 4. Wpływ współdziałania dawek azotu z odmianami na zamieranie karp wierzby

Table 4. Effect of nitrogen doses interaction with the cultivars on the withering of willow rootstocks

\begin{tabular}{|c|c|c|c|c|c|c|c|c|c|c|c|}
\hline \multirow{2}{*}{$\begin{array}{c}\text { Dawki azotu } \\
\text { Doses of nitrogen } \\
{[\mathrm{kg} / \mathrm{ha} \mathrm{N}]}\end{array}$} & \multicolumn{11}{|c|}{ Procent zamarłych karp u odmian - Percent of dead rootstocks according to cultivars } \\
\hline & 1047 & 1054 & $1047 \mathrm{D}$ & Start & Sprint & Turbo & Ekotur & Olof & Jorr & Tordis & $\begin{array}{c}\text { średnia } \\
\text { mean }\end{array}$ \\
\hline 0 & 6,1 & 3,9 & 2,5 & 4,8 & 4,5 & 5,0 & 0,9 & 8,6 & 8,4 & 5,9 & 5,1 \\
\hline 60 & 7,7 & 8,6 & 2,9 & 11,8 & 15,0 & 1,6 & 0,5 & 11,8 & 5,5 & 2,3 & 6,8 \\
\hline 120 & 9,7 & 11,3 & 10,9 & 17,9 & 18,8 & 11,4 & 3,9 & 11,8 & 9,7 & 4,3 & 11,0 \\
\hline 180 & 17,7 & 16,5 & 22,3 & 21,4 & 18,6 & 18,6 & 6,1 & 14,3 & 16,4 & 13,8 & 16,6 \\
\hline $\begin{array}{l}\operatorname{NIR}(0,05) \\
\operatorname{LSD}(0.05)\end{array}$ & \multicolumn{10}{|c|}{$7,0^{*}$} & $2,2 * *$ \\
\hline
\end{tabular}

Istotność przy poziomie: ${ }^{*} \alpha=0,05 ;{ }^{*} \alpha=0,001-$ Significance at: $*_{\alpha} \alpha=0.05 ; * * \alpha=0.001$

Tabela 5. Wpływ współdziałania częstotliwości koszenia wierzby na poletku z odmianami na zamieranie karp wierzby

Table 5. Effect of interaction of frequency of willow harvesting in the plot with the cultivars on the withering of willow rootstocks

\begin{tabular}{|c|c|c|c|c|c|c|c|c|c|c|c|}
\hline \multirow{2}{*}{$\begin{array}{l}\text { Częstotliwość } \\
\text { koszenia wierzby } \\
\text { Frequency } \\
\text { of willow } \\
\text { harvesting }\end{array}$} & \multicolumn{11}{|c|}{ Procent zamarłych karp u odmian - Percent of dead rootstocks according to cultivars } \\
\hline & 1047 & 1054 & $1047 \mathrm{D}$ & Start & Sprint & Turbo & Ekotur & Olof & Jorr & Tordis & $\begin{array}{c}\text { średnia } \\
\text { mean }\end{array}$ \\
\hline $2 \times$ & 14,8 & 15,7 & 15,5 & 24,5 & 25,5 & 11,4 & 2,4 & 11,7 & 12,9 & 6,2 & 14,1 \\
\hline $1 \times$ & 5,7 & 4,4 & 3,8 & 3,5 & 3,0 & 7,0 & 3,3 & 11,5 & 7,1 & 7,0 & 5,6 \\
\hline $\begin{array}{l}\text { NIR }(0,05) \\
\operatorname{LSD}(0.05)\end{array}$ & \multicolumn{10}{|c|}{$5,0^{*}$} & $1,6^{*}$ \\
\hline
\end{tabular}

Istotność przy poziomie: ${ }^{*} \alpha=0,001-$ Significance at: ${ }^{*} \alpha=0.001$

Tabela 6. Wpływ współdziałania częstotliwości koszenia wierzby na poletku z dawkami azotu

Table 6. Effect of interaction of frequency of willow harvesting with doses of nitrogen

\begin{tabular}{c|c|c|c|c}
\hline \multirow{2}{*}{$\begin{array}{c}\text { Częstotliwość koszenia wierzby } \\
\text { Frequency of willow harvesting }\end{array}$} & \multicolumn{4}{|c}{$\begin{array}{c}\text { Procent zamarlych karp dla różnych dawek azotu } \\
\text { Percent of dead rootstocks at different nitrogen doses }\end{array}$} \\
\cline { 2 - 5 } & $0 \mathrm{~kg} / \mathrm{ha} \mathrm{N}$ & $60 \mathrm{~kg} / \mathrm{ha} \mathrm{N}$ & $120 \mathrm{~kg} / \mathrm{ha} \mathrm{N}$ & $180 \mathrm{~kg} / \mathrm{ha} \mathrm{N}$ \\
\hline $2 \times$ & 5,0 & 9,4 & 16,1 & 25,7 \\
\hline $1 \times$ & 5,1 & 4,2 & 5,8 & 7,4 \\
\hline NIR $(0,05)-$ LSD $(0.05)$ & \multicolumn{4}{|c}{$3,1^{*}$} \\
\hline
\end{tabular}


Wpływ częstotliwości zbioru i współdziałania tego czynnika $\mathrm{z}$ odmianami zestawiono $\mathrm{w}$ tabeli 5 . Ten czynnik, wiąże się $\mathrm{z}$ częstotliwością zbioru $\mathrm{w}$ pierwszej 4-letniej rotacji. Przy 1-krotnym koszeniu w pierwszej 4-letniej rotacji (II rząd poletka) zamarło przeciętnie 5,6\% karp, a przy 2-krotnym - 14,1\% (I rząd), tzn. 2,5-krotnie więcej. Uszeregowanie odmian pod względem wzrostu ilości zamarłych karp z powodu 2-krotnego koszenia w stosunku do 1-krotnego koszenia, od największych wartości do najmniejszych, było następujące: Sprint (8,5-krotnie), Start (7,0-krotnie), 1047D (4,2-krotnie), 1054 (3,6-krotnie), 1047 (2,6-krotnie), Jorr (1,8-krotnie), Turbo (1,6 krotnie), Olof (1,0-krotnie), Tordis (0,9-krotnie) i Ekotur (0,7-krotnie). Oceny te klasyfikują odmiany pod względem reakcji na zamieranie karp przy zwiększonej częstotliwości koszenia jako: bardzo silnie reagujące - Sprint i Start, silnie reagujące - 1047D, 1054 i 1047, średnio reagujące Jorr i Turbo oraz nie reagujące - Olof, Tordis i Ekotur.

Wpływ współdziałania częstotliwości koszenia oznaczonej jako rzędów na poletku $\mathrm{z}$ dawkami nawożenia azotem, zestawiono w tabeli 6, z którego wynika, że zamieranie karp nasilało się przy większych dawkach nawożenia azotem, szczególnie na rzędzie I, gdzie 2-krotnie koszono wierzbę. Uszeregowanie dawek azotu pod względem zamarłych karp pomiędzy rzędem I a II od największych do najmniejszych wartości było następujące: dawka $180 \mathrm{~kg} / \mathrm{ha} \mathrm{N}$ - 3,5-krotnie, dawka $120 \mathrm{~kg} / \mathrm{ha} \mathrm{N}-$ 2,8-krotnie, dawka $60 \mathrm{~kg} / \mathrm{ha} \mathrm{N}-2,2$-krotnie i dawka $0 \mathrm{~kg} / \mathrm{ha} \mathrm{N}-1,0$-krotnie.

W literaturze polskiej są różne kryteria optymalnej obsady zrzezów na hektarze: 30-32 tys. (Dubas i Tomczyk 2005), 17,6-22,0 tys. roślin/ha (Faber i wsp. 2009), 8-20 tys. roślin (Szczukowski i wsp. 2004), 10-20 tys. (Szczukowski 2012). Szczukowski i wsp. (2004) zalecaja, aby przy zbiorze w cyklach jednorocznych sadzić 40-60 tys. zrzezów na hektarze, gdyż zwiększenie obsady z 20 tys. do 40-60 tys. roślin/ha istotnie zwiększa plon świeżej biomasy. Faber i wsp. (2009) zalecają, aby na glebach słabszych sadzić 22,0 tys. roślin/ha, a na glebach żyźniejszych 17,6 tys. roślin/ha. Autorzy ci zauważają, że wyniki badań szwedzkich i angielskich wskazuja, że w korzystnych warunkach wilgotnościowych uzasadnione jest zmniejszenie obsady roślin wierzby do 10-13 tys./ha. Według Caslin i wsp. (2004) w Północnej Irlandii sadzi się 18 tys./ha zrzezów z wyliczeniem, że finalnie na plantacji komercyjnej pozostanie 15 tys./ha roślin. Podobne zalecenia co do gęstości sadzenia wierzby na cele energetyczne występują we wschodniej części Kanady (Guidi i wsp. 2013), Anglii, Szkocji, Szwecji (Defra 2004; Wickham i wsp. 2010). Cytowane dane wskazuja, że zalecenia zagęszczenia łanu wierzby wynikają ze stosowanej technologii uprawy i różnią się nieco dla warunków Polski oraz Szwecji, Anglii i Kanady. Jednak w literaturze brak jest wieloletnich obserwacji dotyczących zamierania karp wierzby na plantacjach. Generalnie przyjmuje się, że na 1-rocznej plantacji powinno pozostać ponad 85-95\% żywych karp w stosunku do zastosowanych nasadzeń (Dubas i Tomczyk 2005), a w warunkach Irlandii przy uprawie wierzby przyjmuje się ubytek 3 tys./ha roślin, tj. $17 \%$ zrzezów wysadzonych. Problem dynamiki zamierania karp wierzby był poruszony w pracach Stolarskiego (2009) oraz Styszki i wsp. (2013). Stolarski (2009) wykazał, że zamieranie karp wierzby w 3-letnim cyklu uprawy, na glebie ciężkiej w okolicach Kwidzyna zależało od: odmiany, gęstości sadzenia oraz częstotliwości zbioru, jednakże nie przekraczało ono $10 \%$ założonej obsady niezależnie od badanego wariantu. W warunkach uprawy na glebach lekkich pod Koszalinem w 4-letnim cyklu uprawy zamarło mniej niż 10\% karp, ale w siódmej wegetacji martwych karp na poletku było od 10\% do 90,8\% (Styszko i wsp. 2013). W cytowanych badaniach u czterech klonów przy nawożeniu kompostem z osadów komunalnych zamieranie karp malało, ale dodatkowe stosowanie nawozu mineralnego $\mathrm{u}$ wszystkich dziewięciu klonów, zwiększyło to zamieranie. W referowanych badaniach wykazano, że na dynamikę zamierania karp wierzby na poletkach największy wpływ miały lata uprawy, nieco mniejszy - częstotliwość koszenia, a mniejszy dawki azotu i odmiany. Badania te pokazują skalę zjawiska, ale nie wskazują na biologiczne przyczyny zamierania karp. Można sądzić, że przyczyną zamierania karp w uprawie polowej są infekcje grzybowe roznoszone podczas zbioru, co może sugerować opracowanie RemleinStarosty i Nijak (2010).

\section{Wnioski / Conclusions}

1. Przy zamieraniu karp wierzby w uprawie polowej na glebie lekkiej wykazano dominujące znaczenie lat odrastania pędów, a nieco mniejsze - częstotliwości zbioru pędów. Znaczenie dawek azotu i odmian oraz interakcji tych czynników było mniejsze niż lat odrastania pędów i częstotliwości zbioru w pierwszej rotacji.

2. Do czwartego roku odrastania pędów zamarło przeciętnie 5,3\% karp, a wzrost ilości martwych karp na poletku nastąpił w piątej i szóstej wegetacji, mimo względnie korzystnego rozkładu opadów.

3. Odmiany wierzby charakteryzowały się zróżnicowaną skłonnością do zamierania karp. W szóstej wegetacji, uszeregowanie odmian pod względem ich skłonności do zamierania było następujące: bardzo silne - Start $(42,4 \%)$, silne - Sprint (31,9\%), średnie - 1054 $(26,8 \%)$, Jorr $(25,0 \%)$, Olof $(24,1 \%), 1047(23,9 \%)$, 1047D $(23,7 \%)$ i Turbo $(20,6 \%)$ oraz małe - Tordis $(13,6 \%)$ i Ekotur $(9,2 \%)$.

4. Wzrost nawożenia azotem w stosunku do obiektów bez nawożenia spowodował nasilenie zamierania karp wierzby o $33,3 \%$ przy dawce $60 \mathrm{~kg} / \mathrm{ha} \mathrm{N}$, o $115,7 \%$ przy dawce $120 \mathrm{~kg} / \mathrm{ha} \mathrm{N}$ i o $225,5 \%$ przy dawce $180 \mathrm{~kg} / \mathrm{ha} \mathrm{N}$.

5. Przy 1-krotnym koszeniu w pierwszej 4-letniej rotacji zamarło przeciętnie 5,6\% karp, a przy 2-krotnym $14,1 \%$.

6. Odmiany wierzby pod względem ich reakcji na zamieranie karp przy zwiększonej częstotliwości koszenia uszeregowano następująco: bardzo silnie reagujące Sprint i Start, silnie reagujące - 1047D, 1054 i 1047, średnio reagujące - Jorr i Turbo oraz niereagujące Olof, Tordis i Ekotur.

W celu wyjaśnienia przyczyn zamierania karp wierzby badania będą dalej kontynuowane. 


\section{Literatura / References}

Caslin B., Finnan J., McCracken A. 2010. Short Rotation Coppice Willow Best Practice Guidelines. Belfast. http://www.seai.ie/ Renewables/Bioenergy/Willow_Best_Practice_Guide_2010.pdf [Accessed: 08.01.2014].

Defra. 2004. Growing Short Rotation Coppice. Defra Publications. London. http.://www.naturalengland.org.ul./Images/short-rotationcoppice_tcm6-4262.pdf [Accessed: 08.01.2014].

Dubas J.W., Tomczyk A. 2005. Zakładanie, pielegnacja i ochrona plantacji wierzb energetycznych. Wyd. SGGW, Warszawa, 105 ss.

Faber A., Kuś J., Matyka M. 2009. Uprawa roślin na cele energetyczne. Wyd. W\&B Wiesław Drzewiński, Warszawa, 28 ss.

Guidi W., Pitre F.E., Labresque M. 2013. Short-Rotation Coppice of Willows for the Production of Biomass in Eastern Canada. http://dx.doi.org/10.5772/51111 [Accessed: 08.01.2014].

GUS 2007-2013. Roczniki statystyczne.

Remlein-Starosta D., Nijak K. 2010. Najważniejsze choroby i szkodniki wierzby uprawianej na cele energetyczne i możliwości ich ograniczania. [The most import ant diseases and pest of short rotation willow and control possibility]. Prog. Plant Prot./Post. Ochr. Roślin 50 (2): 977-986.

Skowera B., Puła J. 2004. Skrajne warunki pluwiometryczne w okresie wiosennym na obszarze Polski w latach 1971-2000. Acta Agrophys. 3 (1): 171-177.

Stolarski J.M. 2009. Agrotechniczne i ekonomiczne aspekty produkcji biomasy wierzby krzewiastej (Salix spp.) jako surowca energetycznego. Wyd. UW-M, Olsztyn, 145 ss.

Styszko L., Boguski A., Fijałkowska D. 2013. Wpływ nawożenia na zamieranie karp wierzby energetycznej przy uprawie na glebie lekkiej. JCEEA XXX, 60 (3/13): 19-28.

Szczukowski S. 2012. Wierzba. s. 10-38. W: „Wieloletnie rośliny energetyczne” (S. Szczukowski, red.). Multico, Oficyna Wydawnicza, Warszawa, 156 ss.

Szczukowski S., Tworkowski J., Stolarski M.J. 2004. Wierzba energetyczna. Wyd. Plantpress, Kraków, 46 ss.

Wickham J., Rice B., Finnan J., McConnon R. 2010. A revive of past and current research on short rotation coppice in Ireland and abroad. COFORD, Dublin. http.://www.coford.ie/media/coford/content/publications/projectreports/SRC.pdf [Accessed: 08.01.2014]. 